\title{
ORIGINAL ARTICLE INDEPENDENT BENEFICIAL IMPACT OF SURGICAL REVASCULARIZATION ON ISCHEMIC LEFT VENTRICULAR DYSFUNCTION
}

\author{
Taimur Ahmed ${ }^{1}$, Arslan Masood ${ }^{2}$, Noor Dastgir ${ }^{2}$ \\ ${ }^{1}$ Punjab Institute of Cardiology, Lahore, Pakistan, ${ }^{2}$ Allama Iqbal Medical College / Jinnah Hospital, Lahore, Pakistan
}

Objectives: To assess the improvement in left ventricular ejection fraction (LVEF) after Coronary artery bypass grafting $(\mathrm{CABG})$ among patients with severe LV dy sfunction.

Methodology: This Quasi experimental study was conducted at Punjab Institute of Cardiology from January to June 2021. One hundred and thirty four patients of severe LV dysfunction with coronary anatomy suitable for CABG were included in the study. Assessment of LVEF was carried out with echocardiography at baseline. All patients underwent CABG under general anaesthesia and were followed-up on 15th day with repeat echocardiography. Pre-CABG and post-CABG EFs were compared and mean changes in EFs were checked for potential effect modifications with gender, diabetes, CAD duration, age and body weight.

Results: The mean LVEFs before and after surgery were $23.63 \pm 1.17 \%$ and $32.11 \pm 1.98 \%$ respectively. Mean improvement in LVEF after CABG was $8.5 \pm 2.7 \%$ (p < 0.001, 95\% CI for difference $8.0-8.9$ ) and did not different significantly according to gender, diabetes, CAD duration, age and body weight $(\mathrm{P}=0.592,0.167,0.506,0.138$ and 0.458 respectively $)$.

Conclusion: Patients of CAD who underwent CABG had improved post-operative LVEFs independent of evaluated potential effect modifiers.

Keywords: Coronary heart disease, Left ventricular function, Coronary artery, Bypass grafting

Citation: Ahmed T, Masood A, Dastgir N. Independent Beneficial Impact of Surgical Revascularization on Ischemic Left Ventricular Dysfunction. Pak Heart J. 2021;54(04):357-360. DOI: https://doi.org/10.47144/phj.v54i4.2110

\section{INTRODUCTION}

Coronary artery disease (CAD) is a significant cause of morbidity and mortality in developed countries. ${ }^{1,2}$ Despite the fact that CAD death rates have reduced globally over the past four decades, it still is responsible for about $33 \%$ of mortality in those aged above 35 years. $^{3}$ Postulations have been made that almost $50 \%$ of middle aged men and $33 \%$ of women living in the United States will develop CAD in one form or the other. ${ }^{4}$ A coronary artery bypass graft $(\mathrm{CABG})$ is a surgical procedure done on patients with established severe CAD for reduction of both symptoms as well as the mortality related to it..$^{5,6}$ Nevertheless, we have seen a $30 \%$ death rate reduction from CAD since the late 20th century. ${ }^{7}$ This has been made possible by the development and establishment of coronary care units, procedures like CABG, percutaneous coronary intervention (PCI), and improved medical therapies including thrombolytics and a repeated stress on modifying lifestyle and adopting a healthier way of living. ${ }^{8}$

After bypass surgery (CABG), cardiac dysfunction especially of the Left Ventricle (LV) is a vital predictor of in hospital death rate. ${ }^{9}$ Despite the improvements in operating techniques, better postoperative care and efforts to protect the myocardium, the risk involved with surgery remains high. ${ }^{10}$ Several researches have concluded that when medical therapy is compared with coronary surgery, the quality of life is better with the latter choice. ${ }^{11,12}$ Patients who have CAD and LV systolic dysfunction have a grave predicted outcome with survival rates around $20-30 \%$ even with maximally optimized medical treatment. ${ }^{13}$

The pre-requisite of LV function to improve with all possible therapies is the fact that patients have a viable myocardium which is identified with noninvasive imaging techniques. ${ }^{14}$ Revascularization of viable nonfunctioning anterior wall muscle is the main contributor to betterment of the systolic function, measured by the ejection fraction (EF). Reduced LVEF, left ventricular re- or non-modelling, and viable myocardium of the anterior wall help in estimating how much ejection fraction will increase post-surgery. This gives a better option to healthcare providers to choose which patients are likely to benefit the most from surgical revascularization. ${ }^{15}$ Postoperative improvement in $\mathrm{EF}$ has been variable in literature with a value as high as $9.9 \% \pm 5.9 .{ }^{16}$ Hexiberqi-Karabidic et al. documented an improvement in EF from $25.6 \pm 5.2 \%$ to $31.08 \pm 5.5 \%$ over a period of 30 days. ${ }^{17}$

The purpose of this research was to evaluate the improvements in LV systolic dysfunction after surgical revascularization in local settings. The local triage system and revascularization strategies differ 
from developed health care systems with regards to delays in early definitive reperfusions and resultant prevalent LV dysfunctions which are likely to be more in severity as well. Subsequent benefit from surgical reperfusion in patients with significant LV dysfunction and coronary anatomies favorable for $\mathrm{CABG}$ is expected to be even greater compared to published western data.

\section{METHODOLOGY}

This Quasi experimental study was conducted at Punjab Institute of Cardiology from January to June 2021.

The protocol was approved by the institutional ethical committee and formal informed consent was obtained from study participants. Consecutive 134 patients were included in the study and the sample size was calculated on the basis of $95 \%$ confidence level, 0.01 absolute precision and the mean change in LVEF $9.9 \pm 5.9 \%$ after $\mathrm{CABG} .{ }^{14}$

Patients aged 40-70 years presenting with acute coronary syndrome (unstable angina, non ST-segment elevation infarction and ST-segment elevation infarction), coronary anatomy suitable for CABG and baseline $\mathrm{EF}<30 \%$ on echocardiography were included in the study.

Patients with previous revascularization and valvular lesions requiring concomitant repair or replacement were excluded. All patients underwent echocardiography for assessment of LVEF at baseline by a single senior cardiologist. The LVEF was calculated on transthoracic echocardiography by cube method using systolic and diastolic M-mode measurements.

All patients underwent $\mathrm{CABG}$ by the same surgical team under general anesthesia. Routine post-operative care and post discharger medications were suggested as per institutional protocols. Repeat echocardiography was performed 15 days after surgery to assess the change in LVEF.

Baseline EF was compared according to gender, diabetes (HBA1C > 7.0\%) and CAD duration by independent sample t-test and age categories and body weight categories were compared for mean baseline EFs by ANOVA. Mean pre-CABG EFs and postCABG EFs were compared by paired-samples t-test. This was followed by comparing the mean changes in EFs among genders, diabetes and CAD duration groups by independent sample t-test and among age categories and body weight categories by ANOVA. Significance level was set at 0.05 .

\section{RESULTS}

Mean age of patients was $56.25 \pm 9.04$ years including $64(47.8 \%)$ males and $70 \quad(52.2 \%)$ females. Mean duration of CAD was $11.92 \pm 6.25$ months and $69(51.5 \%)$ had diabetes mellitus. Mean baseline EF of subjects before CABG was $23.6 \pm$ $1.7 \%$ and did not differ significantly according to gender, diabetes, CAD duration, age and body weight $(\mathrm{p}=0.659,0.781,0.259,0.105$ and 0.0308 respectively) (Table 1). The mean EF 15 days post CABG was $32.1 \pm 1.9 \%$. Mean change in EF from baseline to 15 days after CABG was $8.5 \pm 2.7 \%$, p< $0.001,95 \% \mathrm{CI}$ for difference 8.0 - 8.9 (Figure 1) and did not different significantly according to gender, diabetes, CAD duration, age and body weight $(\mathrm{p}=$ $0.592,0.167,0.506,0.138$ and 0.458 respectively) (Table 2).

Table 1: Baseline ejection fraction distribution according to gender, diabetes, CAD duration, age groups and weight groups

\begin{tabular}{|c|c|c|c|}
\hline \multirow{2}{*}{$\begin{array}{l}\text { Potential effect } \\
\text { modifiers }\end{array}$} & Baseline EF & \multirow{2}{*}{$\begin{array}{l}\text { 95\% CIs for } \\
\text { difference }\end{array}$} & \multirow{2}{*}{$\begin{array}{c}P- \\
\text { value }\end{array}$} \\
\hline & Mean \pm SD & & \\
\hline \multicolumn{4}{|l|}{ Gender } \\
\hline Males & $23.7 \pm 1.7$ & \multirow{2}{*}{$-0.46-0.72$} & \multirow{2}{*}{0.659} \\
\hline Females & $23.6 \pm 1.8$ & & \\
\hline \multicolumn{4}{|l|}{ Diabetes } \\
\hline Diabetics & $23.6 \pm 1.7$ & \multirow{2}{*}{$-0.67-0.50$} & \multirow{2}{*}{0.781} \\
\hline Non-diabetics & $23.7 \pm 1.8$ & & \\
\hline \multicolumn{4}{|l|}{ CAD Duration } \\
\hline Up to 12 months & $23.7 \pm 1.7$ & \multirow{2}{*}{$0.19-0.29$} & \multirow{2}{*}{0.259} \\
\hline$>12$ months & $23.5 \pm 1.8$ & & \\
\hline \multicolumn{2}{|l|}{ Age categories } & $\begin{array}{l}95 \% \text { CIs for } \\
\text { mean }\end{array}$ & - \\
\hline$<45$ years & $23.7 \pm 1.6$ & $22.8-24.6$ & \multirow{3}{*}{0.105} \\
\hline 45 to 60 years & $23.9 \pm 1.7$ & $23.5-24.4$ & \\
\hline$>60$ years & $23.3 \pm 1.7$ & $22.8-23.7$ & \\
\hline \multicolumn{4}{|c|}{ Weight categories } \\
\hline Normal & $23.3 \pm 1.7$ & $22.6-23.9$ & \multirow{3}{*}{0.308} \\
\hline Over-weight & $23.9 \pm 1.8$ & $23.3-24.4$ & \\
\hline Obese & $23.6 \pm 1.6$ & $23.2-24.1$ & \\
\hline
\end{tabular}

$E F=$ ejection fraction, $C I=$ confidence interval, $C A D=$ coronary artery disease

Table 2: Pre-CABG to Post-CABG change in ejection fraction among various groups

\begin{tabular}{|l|c|c|c|}
\hline $\begin{array}{l}\text { Potential effect } \\
\text { modifiers }\end{array}$ & Change in EF & $\begin{array}{c}\text { 95\% CIs for } \\
\text { difference }\end{array}$ & $\begin{array}{c}\text { P- } \\
\text { value }\end{array}$ \\
\cline { 2 - 3 } Gender & $8.3 \pm 2.6$ & $-1.2-0.69$ & 0.592 \\
\hline Males & $8.6 \pm 2.9$ & & \\
\hline Females & $8.8 \pm 2.6$ & \multirow{2}{|c|}{$-0.28-1.6$} & 0.167 \\
\hline Diabetes & $8.1 \pm 2.9$ & & \\
\hline Diabetics & $8.6 \pm 2.8$ & \multirow{2}{|c|}{$-0.63-1.2$} & 0.506 \\
\hline Non-diabetics & $8.3 \pm 2.7$ & $\begin{array}{c}\text { 95\% CIs for } \\
\text { mean }\end{array}$ & \\
\hline CAD Duration & $6.9-10.2$ & 0.138 \\
\hline Up to 12 months & 12 months &
\end{tabular}




\begin{tabular}{|c|c|c|c|}
\hline 45 to 60 years & $8.0 \pm 2.8$ & $7.3-8.7$ & \\
\hline$>60$ years & $9.0 \pm 2.6$ & $8.3-9.7$ & \\
\hline \multicolumn{4}{|c|}{ Weight categories } \\
\hline Normal & $9.0 \pm 3.0$ & $7.9-10.1$ & \multirow{3}{*}{0.458} \\
\hline Over-weight & $8.3 \pm 2.8$ & $7.5-9.2$ & \\
\hline Obese & $8.3 \pm 2.6$ & $7.7-9.0$ & \\
\hline
\end{tabular}

$E F=$ ejection fraction, $C I=$ confidence interval, $C A D=$ coronary artery disease

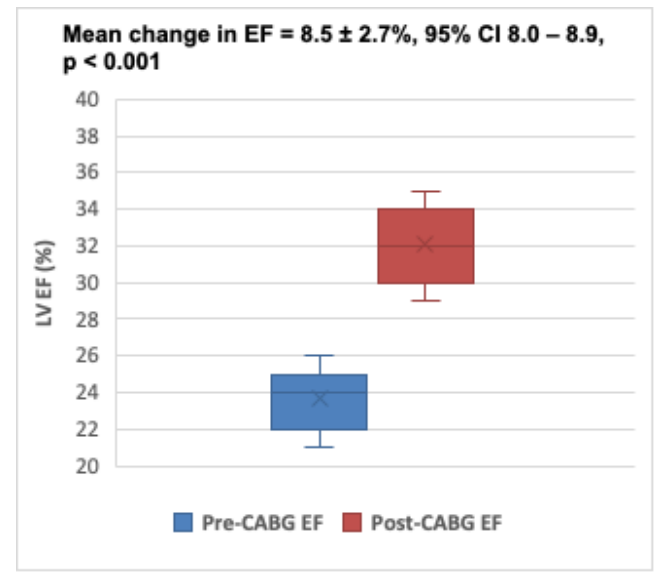

Figure 1: Trends of Pre-CABG and Post-CABG ejection fractions

\section{DISCUSSION}

The 15 days post-surgical reperfusion improvement $(8.5 \pm 2.7 \%, 95 \%$ CI $8.0-8.9)$ was similar to published data form developed systems. ${ }^{15,16}$ None of the independent predictors (gender, diabetes, CAD duration, age and body weight) could show a significant impact on mean change in EF after surgical revascularization.

Koene in his study revealed that a reduction in LVEF with bypass surgery was seen in patients with normal LVEF prior to the operation, however, the myocardial activity got better in those with decreased preoperative LVEF. ${ }^{18}$ Many studies have revealed that patients with systolic dysfunction tend to have a better ejection fraction after CABG. ${ }^{19} \mathrm{~A}$ mention of the STICH trial is necessary here as it was the only prospective, randomized, controlled trial to precisely evaluate the role of CABG in patients with severe left ventricular systolic dysfunction $(\mathrm{EF} \leq 35 \%)$. A post hoc subgroup analysis of this trial showed a noteworthy progress in both left ventricular size and function in those individuals with a higher baseline left ventricular end-systolic dimensions. ${ }^{20}$

Diabetes mellitus has been shown to be individually correlated with increased death rates among individuals with ischemic cardiomyopathy due to an acceleration of cardiac dysfunction in patients with ischemic heart failure. ${ }^{21} \mathrm{~A}$ total of 5,259 patients undergoing $\mathrm{CABG}$ in the United Kingdom, were studied by Rajakaruna and colleagues who then determined that diabetes mellitus is a 5 year mortality predictor on its own and of lower 5-year cardiac related event-free survival. ${ }^{22}$

The data in STICH trial recognized a number of patient features that have an influence on the risk of 30-day postoperative complications and mortality. Ironically, some of these variables, such as LVEF and a severe CAD also predict who will improve most with surgery. Valvular dysfunction of the mitral apparatus causing regurgitation also predicts patients at greater risk, but again, repair of the lesion tends to have a significant beneficial effect, both short and long term and should be done when suitable. ${ }^{23}$ Other elements that intensify risk and are also difficult to modify, such as renal loss of function ${ }^{24,25}$, elderly patients, and the occurrence of atrial arrythmias, among others, may make surgeons to choose operative procedures that limit cardiopulmonary bypass time. ${ }^{24}$

The outcome of cardiac surgery for patients of severe coronary artery disease especially with lower ejection fractions has improved over time as also seen in our study and other than providing as a safety net for the severe coronary artery disease the improvement in the ejection fraction and over all left ventricular function adds another jewel to its crown.

The major limitation of this study was its limited sample size. The time interval between revascularization and the subsequent determination of the EF is a factor that should be taken into account, given that if the evaluation takes place very early, there may be a certain degree of myocardial stunning, which leads to the underestimation of the EF. Although the minimum interval in our study was 15 days, the number of patients with improved EF may have been greater if we have performed a gated SPECT at a later date but due to a low resource setting it was not possible, however our findings do have a clinical significance. A larger future study is suggested with longer follow-ups and advanced imaging modalities.

\section{CONCLUSION}

Patients of CAD who underwent CABG had improved post-operative LVEFs independent of evaluated potential effect modifiers. Surgical revascularization in cases of LV dysfunction leads to significant early improvements.

\section{AUTHORS' CONTRIBUTION}

TA: Concept and design, data acquisition, interpretation, drafting, final approval, and agree to be accountable for all aspects of the work. AM, ND: Data acquisition, interpretation, drafting, final approval and agree to be accountable for all aspects of the work. 
Conflict of interest: Authors declared no conflict of interest.

\section{REFERENCES}

1. Scherrenberg M, Wilhelm M, Hansen D, Völler H, Cornelissen V, Frederix I, et al. The future is now: A call for action for cardiac telerehabilitation in the COVID-19 pandemic from the secondary prevention and rehabilitation section of the European Association of Preventive Cardiology. Eur J Prev Cardiol. 2021;28(5):524-40.

2. Adil M, Khan I, Hassan Z, Habib SA, Jibran MS, Nawaz Sr T. One year outcomes after percutaneous coronary intervention in diabetics with stable ischemic heart disease: A single-center comparative study. Cureus. 2021;13(1):E12731.

3. Sousa-Uva M, Neumann FJ, Ahlsson A, Alfonso F, Banning AP, Benedetto U, et al. ESC scientific document group. 2018 ESC/EACTS guidelines on myocardial revascularization. Eur J Cardiothorac Surg. 2019;55:4-90.

4. Benjamin EJ, Blaha MJ, Chiuve SE, Cushman M, Das SR, Deo R, et al. Heart disease and stroke statistics-2017 update: A report from the American Heart Association. Circulation. 2017;135(10):e146-e603.

5. Levine GN, Bates ER, Bittl JA, Brindis RG, Fihn SD, Fleisher LA, et al. 2016 ACC/AHA guideline focused update on duration of dual antiplatelet therapy in patients with coronary artery disease: A report of the American College of Cardiology/American heart association task force on clinical practice guidelines. Circulation. 2016;134(10):e123-e55.

6. Bonow RO, Castelvecchio S, Panza JA, Berman DS, Velazquez EJ, Michler RE, et al. Ischemic left ventricular dysfunction: Severity of remodeling, myocardial viability and survival after surgical revascularization. JACC Cardiovase Imaging. 2015;8(10):1121-9.

7. Saleh M, Ambrose JA. Understanding myocardial infarction. F1000Res. 2018;7;F1000 Faculty Rev-1378.

8. Nauta JF, Hummel YM, Van Melle JP, Van der Meer P, Lam CS, Ponikowski $\mathrm{P}$, et al. What have we learned about heart failure with mid-range ejection fraction one year after its introduction? Eur J Heart Fail. 2017;19:1569-73.

9. Lomivorotov VV, Efremov SM, Kirov MY, Fominskiy EV, Karaskov AM. Low-cardiac-output syndrome after cardiac surgery. J Cardiothorac Vasc Anesth. 2017;31(1):291-308.

10. Parikh PB, Bhatt DL, Bhasin V, Anker SD, Skopicki HA, Claessen BE, et al. Impact of percutaneous coronary intervention on outcomes in patients with heart failure. J Am Coll Cardiol. 2021;77(19):2432-47.

11. Tuijis DJF, Milojevic M, Stone GW, Puakas JD, Serruys PW, Sabik JF, et al. Impact of left ventricular ejection fraction on clinical outcomes after left main coronary artery revascularization: results from the randomized EXCEL trial. Eur J Heart Fail. 2020;22,871-9.

12. Velazquez EJ, Bonow RO. Revascularization in severe left ventricular dysfunction. J Am Coll Cardiol. 2015;65(6):615-24.

13. Bonow RO, Castelvecchio S, Panza JA, Berman DS, Velazquez EJ, Michler RE, et al. Ischemic left ventricular dysfunction: severity of remodeling, myocardial viability and survival after surgical revascularization. J Am Coll Cardiol Cardiovasc Imag. 2015;8(10):1121-9.

14. Kandolin RM, Wiefels CC, Mesquita CT, Chong AY, Boland P, Glineur D, et al. The current role of viability imaging to guide revascularization and therapy decisions in patients with heart failure and reduced left ventricular function. Can J Cardiol. 2019;35(8):1015-29.

15. Mandegar MH, Yousefnia MA, Roshanali F, Rayatzadeh H, Alaeddini F. Interaction between two predictors of functional outcome after revascularization in ischemic cardiomyopathy: left ventricular volume and amount of viable myocardium. J Thorac Cardiovasc Surg. 2008;136(4):930-6.

16. Haxhibeqiri-Karabdic I, Hasanovic A, Kabil E, Straus S. Improvement of ejection fraction after coronary artery bypass grafting surgery in patients with impaired left ventricular function. Med Arch. 2014:68(5):332-4

17. Koene RJ, Kealhofer JV, Adabag S, Vakil K, Florea VG. Effect of coronary artery bypass graft surgery on left ventricular systolic function. J Thorac Dis. 2017;9(2):262-70.

18. Vakil K, Florea V, Koene R, Kealhofer JV, Anand I, Adabag S. Effect of coronary artery bypass grafting on left ventricular ejection fraction in men eligible for implantable cardioverterdefibrillator. Am J Cardiol. 2016;117(6):957-60.

19. Michler RE, Rouleau JL, Al-Khalidi HR, Bonow RO, Pellikka PA, Pohost GM, et al. Insights from the STICH trial: change in left ventricular size after coronary artery bypass grafting with and without surgical ventricular reconstruction. J Thorac Cardiovasc Surg. 2013;146(5):1139-45

20. Shah S, Benedetto U, Caputo M, Angelini GD, Vohra HA. Comparison of the survival between coronary artery bypass graft surgery versus percutaneouscoronary intervention in patients with poor left ventricular function (ejection fraction $<30 \%$ ): A propensity-matched analysis. Eur J Cardiothorac Surg. 2019;55:238-46

21. Wolff G, Dimitroulis D, Andreotti F, Kolodziejczak M, Jung C, Scicchitano P, et al. Survival benefits of invasive versus conservative strategies in heart failure in patients with reduced ejection fraction and coronary artery disease: A meta-analysis. Circ Heart Fail. 2017;10:e003255.

22. Wrobel K, Stevens SR, Jones RH, Selzman CH, Lamy A, Beaver $\mathrm{TM}$, et al. Influence of baseline characteristics, operative conduct, and postoperative course on 30-day outcomes of coronary artery bypass grafting among patients with left ventricular dysfunction: Results from the Surgical Treatment for Ischemic Heart Failure (STICH) trial. Circulation. 2015;132(8):720-30.

23. Yoo JS, Kim JB, Jung SH, Choo SJ, Chung CH, Lee JW. Coronary artery bypass grafting in patients with left ventricular dysfunction: predictors of long-term survival and impact of surgical strategies. Int J Cardiol. 2013;168(6):5316-22.

24. Mooney JF, Croal BL, Cassidy S, Lee VW, Chow CK, Cuthbertson $\mathrm{BH}$, et al. Relative value of cystatin $\mathrm{C}$ and creatininebased estimates of glomerular filtration rate in predicting longterm mortality after cardiac surgery: A cohort study. BMJ Open. 2019;9(9):e029379.

25. Amin MN, Hussain AB, Ali AM, Raja AM, Shaiq PA. Assessment of pre \& post serum creatinine levels in CABG patients of northern Pakistan. Atherosclerosis. 2020;315:e175.

\section{Address for Correspondence:}

Dr. Arslan Masood, Associate Professor, Department of Cardiology, Allama Iqbal Medical College / Jinnah Hospital, Lahore, Pakistan.

Email: $\underline{\text { dr_arslanmasood@hotmail.com }}$ 